(С) С.В. Васильев, С.Б. Боруцкая, Д.В. Васильев

\title{
АНТРОПОЛОГИЧЕСКИЙ АНАЛИЗ ПОГРЕБЕНИЙ ЭПОХИ БРОНЗЫ ИЗ КУРГАНА № 1 МОГИЛЬНИКА «БОГОМОЛЬНЫЕ ПЕСКИ»*
}

\begin{abstract}
В данной работе мы вводим в научный оборот результаты изучения палеоантропологического материала из Нижнего Поволжья из Курганной группь «Богомольные пески», оставленной населением эпохи бронзы. Данный курганный могильник располагался в Астраханской области в Енотаевском районе. В статье приводятся итоги изотопного анализа костного материала, а также результаты исследования посткраниальных скелетов. Изотопный анализ показал, что основой рачиион у жителей эпохи бронзы территории современной Астраханской области были мясо птищь и хищных рыб. Кроме того, изотопный анализ обнаружил, что у детей мясная пища занимала большее место в диете, чем у взросльх мужчин. Морфологический анализ посткраниального скелета выявил относительную удлинённость плечевой кости. Реконструированная прижизненная длина тела мужчин оказалась выше средней.
\end{abstract}

Ключевые слова: Нижнее Поволюье, эпоха бронзы, остеология, остеоскопия, пропоричи и массивность костей, палеодиета

\section{Введение}

Весной 2019 года в рамках реализации проекта «Астраханские курганы археологической экспедицией Астраханского музея-заповедника, ООО «Археоцентр» и исторического факультета Астраханского государственного университета (руководитель исследований - научный сотрудник АМЗ А.А. Тимофеев) проводились охранные раскопки кургана 1 в курганном могильнике «Богомольные пески-І» в Енотаевском районе Астраханской области в 3,5 км к юго-востоку от южного выезда из села Никольское.

Васильев Сергей Владимирович - д.и.н., главный научный сотрудник, заведующий Центром физической антропологии Института этнологии и антропологии РАН (Москва, Ленинский пр. 32-а). Эл. почта: vasbor1@yandex.ru. Vasilyev, Sergey V. - Institute of Ethnology and Anthropology, RAS (Moscow, Leninsky Pr. 32-a). E-mail: vasbor1@yandex.ru

Боруцкая Светлана Борисовна - к.б.н., старший научный сотрудник кафедры антропологии биологического факультета МГУ имени М.В.Ломоносова (Москва, Ленинские горы $1 / 12$ ) Эл. почта: vasbor1@yandex.ruBorutskaya, Svetlana B. - Moscow state University. (Moscow, Leninskie goru, 1/12). E-mail: vasbor1@yandex.ru

Васильев Дмитрий Викторович - к.и.н., руководитель Школы «Археология Нижнего Поволжья» Астраханского государственного университета (г. Астрахань, РФ, ул. Татищева, д. 20a). Эл. почта: hvdv@mail.ru._Vasilyev, Dmitriy V. - Astrakhan state University (Astrakhan, Tatishcheva street, 20A). E-mail: hvdv@mail.ru

* Публикуется в соответствии с планом научно-исследовательских работ Института этнологии и антропологии РАН 
Курганный могильник располагается на невысоком покрытом древними дюнами водоразделе, ориентированном с юго-запада на северо-восток на правом берегу p. Волги, в 2,5 км к западу от надпойменной террасы. Он состоит из трёх курганов высотой около 50-80 см и около 40 м в диаметре. Курганы вытянуты цепочкой с Северо-Востока на Юго-Запад и отстоят на 20 м друг от друга. Курган № 1 занимал центральное положение в группе, с СВ располагается курган № 2, с Ю3 цепочку замыкает курган № 3.

В ходе спасательных раскопок в кургане № 1 было обнаружено 14 погребений, из которых одно, № 14, оказалось разрушено более поздними захоронениями и на момент раскопок не содержало костяка. Был обнаружен только небольшой участок могильной ямы, заполненной рыхлой супесью с примесью красной охры. Видимо, именно это захоронение, относившееся к эпохе бронзы, и являлось основным в кургане. Ещё шесть погребений относились к эпохе бронзы, пять - к эпохе раннего железного века, два - к эпохе средневековья.

Первоначальная насыпь кургана № 1 высотой около 80 см была возведена в эпоху раннего бронзового века (около 4500 лет назад) представителями полтавкинского этапа ямной культуры. Вокруг насыпи был сооружён кольцевой ров шириной до 2 м и диаметром 25 м. С южной стороны рва имелась перемычка шириной около 2 м.

\section{Материалы и методы}

В 2019 году были исследованы скелетные останки захоронений в кургане, относящиеся только к эпохе бронзы. Скелеты имели разную степень сохранности. В основном это были сильно фрагментарные скелеты, кости сильно разрушены, а целых черепов вообще обнаружено не было. Поэтому, к сожалению, провести краниологическое исследование нам не удалось. Остеологический анализ дал некоторые результаты. Приведем краткое описание материала из погребений и палеопатологический анализ.

\section{Погребение 11. Впускное. III тыс. до н.э.}

Похороненный индивид лежал скорченно на правом боку. Скелет крайне плохой сохранности. Принадлежал мужчине 25-30 лет. Возраст определен, в первую очередь, по степени стертости зубов. Признаков заболеваний на фрагментах костей черепа и зубах не обнаружено. Необходимо отметить большой размер зубов, особенно моляров, - тавродонтию. Состояние зубов соответствует возрасту. Так, бугорки верхних и нижних первых моляров частично стерты, вторых моляров стерты в меньшей степени. Третьи моляры - фактически без изменений. Коронки резцов стерты приблизительно на пятую часть высоты. Можно предположить, например, что такая сильная стертость резцов связана с частым использованием зубов для жевания и откусывания кожи в процессе скорняжной работы. То есть резцы могли использоваться в качестве своего рода скорняжного инструмента. Но это не более, чем предположение. Посткраниальный скелет сильно разрушен. На имеющихся фрагментах костей патологий также не обнаружено.

\section{Погребение 6. Впускное. II тыс. до н.э.}

Скелет плохой сохранности. Принадлежал ребенку 11-12 лет. Эпифизы длинных костей не приросли к диафизам. У всех фаланг пальцев кистей и пястных костей (кро- 
ме одной) не приросли основания. К пяточным костям не прирос пяточный бугор. То есть, в целом, возраст индивида был до 13-14 лет (Пашкова 1963). Удалось измерить фрагмент лучевой кости. Очень приблизительное восстановление ее длины и последующая попытка определить возраст дали результат - чуть старше, чем 12 лет. Однако разные схемы дают несколько разный результат. Более надежно определение возраста детских скелетов по уровню развития дентиции. Исследованы фрагменты черепа, в том числе, фрагменты верхних челюстей. Выросли постоянные клыки и вторые премоляры, а также вторые постоянные моляры. Их корни практически закончили развитие. То есть, биологический возраст по верхним челюстям определяется как около 12 лет. На фрагментарной нижней челюсти имеются первые постоянные моляры, еще не сменились молочные вторые моляры, а вторые премоляры находятся в закладке под молочными молярами. Это соответствует возрасту 10-11 лет. Второй премоляр, судя по альвеоле, прорезался, но еще полностью не вырос. В целом биологический возраст ребенка по показателям степени развития зубной системы составил 11-12 лет. На клыках и премолярах нижней челюсти отмечена эмалевая гипоплазия. Это говорит о нехватке пищи, витаминов и вероятных болезнях в период развития коронок этих зубов, то есть примерно, когда ребенку было 4-6 лет.

\section{Погребение 7. Впускное. II тыс. до н.э.}

Скелет, лежавший в скорченном положении в погребении, принадлежал мужчине 25-30 лет. Скелет имел среднюю степень сохранности. Некоторые кости удалось измерить и рассчитать определенные индексы пропорций и массивности костей, а также ряд других показателей. Результаты будут описаны ниже.

\section{Погребение 8. Впускное. II тыс. до н.э.}

Скелет принадлежал мужчине 35-40 лет. Возраст определяли по состоянию позвонков, фаланг пальцев, структур суставов, ушковидной поверхности тазовых костей. Череп не сохранился. Посткраниальный скелет имел достаточную сохранность, чтобы провести измерения и рассчитать индексы пропорций конечностей, массивности (или прочности) костей, степени укрепленности разных ярусов длинных костей конечностей, рассчитать прижизненную длину тела этого индивида, описать степень развития мышечного рельефа, выявить аномалии и патологии скелета.

\section{Погребение 9. Впускное. II тыс. до н.э.}

Скелет плохой сохранности принадлежал ребенку 5-6 лет. Возраст определялся по степени прорезывания зубов, то есть по уровню развития зубной системы. Также учитывался и уровень развития костей посткраниального скелета. На большеберцовых костях видны четкие, многочисленные линии Гарриса.

\section{Погребение 10. Впускное. II тыс. до н.э.}

Скелет очень плохой сохранности. Принадлежал мужчине 20-25 лет. Возраст определен по уровню развития зубной системы и костей посткраниального скелета. К сожалению, фрагментарность костей не позволила провести измерения. На зубах выявлен светло-охристый несильный зубной камень. 
Было проведено измерение костей посткраниального скелета из двух погребений № 7 и № 8 по стандартной остеометрической программе с некоторыми нашими добавлениями. Способ тех или иных измерений костей скелета основывался на правилах, описанных в работе В.П. Алексеева «Остеометрия» (Алексеев 1966). Для описания развития мышечного рельефа нами была использована схема Федосовой (Федосова 1986).

В лаборатории археологической технологии ИИМК РАН были проведены изотопные анализы (изотопы углерода и азота) на предмет определения рациона питания.

\section{Результаты исследования}

У скелета из погребения № 7 относительно не плохо сохранилась правая часть. Именно по этой стороне и были произведены измерения. Кроме того, в наличии были фрагменты черепа и изолированные зубы. В таблице 1 приведены результаты расчета индексов пропорций конечностей и длины тела при жизни.

Таблица 1

Индексы пропорций конечностей, показателей таза, прижизненная длина тела индивида из погребения № 7

\begin{tabular}{l|c}
\hline Индекс & Правая сторона \\
\hline Плече-бедренный индекс (\%) & 75,84 \\
\hdashline Луче-плечевой индекс (\%) & 75,22 \\
\hdashline Прижизненная длина тела (см) & 169,0 см \\
\hline
\end{tabular}

Для сравнения были использованы данные о размахе вариаций признака у человека современного типа, взятые из работ Рогинского и Левина (Рогинский, Левин 1978), Хрисанфовой (Хрисанфова 1978) и наших собственных. Величина плече-бедренного индекса указывает на сильно удлиненное плечо (или же выраженно укороченный бедренный отдел ноги). Луче-плечевой индекс соответствует чуть ниже среднего соотношению длин проксимального и медиального отделов руки. Практически это среднее соотношение. То есть, луче-плечевой показатель говорит нам о соотношении, более характерном для континентального адаптивного типа.

Прижизненная длина тела рассчитана по длине правой бедренной кости с использованием формул Пирсона и Ли, а также Дипертюи и Хеддена (цит. по Алексееву, 1966). В среднем рост мужчины из погребения № 7 составил 169,0 см. То есть у него был рост выше среднего (по Мартину, циит. по Рогинскому и др., 1978).

В таблице 2 приведены результаты расчета индексов прочности (массивности) костей конечностей.

К сожалению, удалось измерить и рассчитать индексы массивности только для нескольких правых костей, так как скелет был неполным.

Плечевая кость. Характеризуется средней степенью массивности и слабой уплощенностью в середине диафиза (что может быть связано со слабым развитие основы дельтовидной бугристости).

Лучевая кость. Высоко массивна и сильно уплощена, хорошо выступает межкостный край. 


\section{Индексы массивности (прочности) и укрепленности костей конечностей индивида из погребения № 7}

\begin{tabular}{|c|c|}
\hline Индекс & Правая сторона \\
\hline Индекс прочности плечевой кости (7/1) & 19,82 \\
\hline Индекс сечения середины диафиза (6/5) & 81,63 \\
\hline Индекс массивности лучевой кости (3/1) & 18,02 \\
\hline Индекс сечения лучевой кости (5/4) & 70,59 \\
\hline Индекс массивности локтевой кости (3/2) & 16,53 \\
\hline Индекс сечения диафиза (11/12) & 83,33 \\
\hline $\begin{array}{l}\text { Индекс сечения верхней части диафиза локтевой кости } \\
\text { (платолении) (13/14) }\end{array}$ & 70,18 \\
\hline Индекс массивности бедренной кости (8/2) & 19,68 \\
\hline Индекс пилястрии бедра (6/7) & 93,33 \\
\hline Индекс прочности бедра (6+7/2) & 12,82 \\
\hline Индекс платимерии бедра (10/9) & 68,0 \\
\hline
\end{tabular}

Локтевая кость. Средне массивная. Слабо уплощенная, межкостный край выступает не сильно. В верхней части диафиза кость сильно сплющена в поперечном направлении, или платоленична. Гребень супинатора выступает несильно.

Бедренная кость. Характеризуется средней степенью массивности. Задний пилястр развит слабо, а сама кость в средней части тела немного уплощена в сагиттальном направлении. В верхней части диафиза кость очень сильно уплощена, или гиперплатимерична.

\section{Остеоскопия}

В таблице 3 приведены результаты остеоскопии, то есть описания степени развития костного рельефа для прикрепления некоторых наиболее важных мышц, кроме того, здесь приведены показатели фенетического описания особенностей костей. Для описания развития мышечного рельефа мы использовали схему В.Н. Федосовой (Федосова 1986), в которую нами были добавлены некоторые признаки, по нашему мнению, также интересные и информативные. Фенетическое описание базировалось на схемах, предложенных в работе В.П. Алексеева «Остеометрия» (Алексеев 1966). 
Таблица 3

Оценка степени развития мышечного рельефа и форма некоторых структур костей посткраниального скелета индивида из погребения № 7

\begin{tabular}{|c|c|}
\hline Кости и структуры & Правая \\
\hline \multicolumn{2}{|l|}{ Плечевая кость } \\
\hline Малый бугорок & 3 \\
\hline Межбугорковая борозда & $3-$ \\
\hline Дельтовидная шероховатость & $1+$ \\
\hline Гребень большого бугорка & 2 \\
\hline Гребень малого бугорка & 2 \\
\hline Гребень супинатора & 2 \\
\hline \multicolumn{2}{|l|}{ Лучевая кость } \\
\hline Лучевая шероховатость & 3 \\
\hline $\begin{array}{l}\text { Межкостный край } \\
\text { Форма межкостного края }\end{array}$ & $\begin{array}{c}2 \\
\text { вогнутый }\end{array}$ \\
\hline Бугорки и бороздки сзади на нижнем конце & 3 \\
\hline \multicolumn{2}{|l|}{ Локтевая кость } \\
\hline Локтевая бугристость & 2 \\
\hline Гребень супинатора & $2-$ \\
\hline Гребень пронатора & 3 \\
\hline Задний край & 2 \\
\hline Межкостный край & 2 \\
\hline \multicolumn{2}{|l|}{ Бедренная кость } \\
\hline Большой вертел & 3 \\
\hline Малый вертел & 3 \\
\hline Межвертельный гребень & $1+$ \\
\hline Межвертельная линия & $1+$ \\
\hline Шероховатая линия (Linea aspera) & 2 \\
\hline Ягодичная шероховатость & 3 \\
\hline Развитие надмыщелков (медиальный/латеральный) & 3 / вероятно, 2 или 3 \\
\hline
\end{tabular}

У правой плечевой кости хорошо развит малый бугорок. Гребни большого и малого бугорков развиты умеренно. Можно предположить значимую нагрузку на мышцы плечевого пояса - вращатели плеча внутрь, и при этом среднюю нагрузку 
на большую грудную мышцу и широчайшую мышцу спины, как вращатели плеча внутрь в разном его положении. А вот отведение плеча и его вращение в отведенном состоянии, видимо, имело еще меньшее значение. Во всяком случае на это указывает очень слабое развитие дельтовидной шероховатости. Гребень супинатора на плечевой кости, впрочем, так же, как и на локтевой кости развит умеренно. Вероятно, в большей степени функцию мышцы-супинатора исполнял бицепс плеча, о чем говорит сильное развитие лучевой шероховатости (3 балл). Можно предположить, что сгибание предплечья (локтевого сустава) имело большого значение при физических работах. У локтевой кости следует отметить очень сильное развитие гребня квадратного пронатора. Возможно, пронация рук также была важна.

На тазовых костях следует указать на очень сильное развитие верхних и нижних передних подвздошных остей, что соответствует хорошему развитию и, вероятно, особой нагрузке на мышцу-напрягатель широкой фасции бедра, портняжную мышцу и прямую головку четырехглавой мышцы бедра. В целом можно предположить большое значение при физических нагрузках сгибания бедра (тазобедренного сустава) (или, по-другому говоря, поднимание бедра).

На бедренной кости следует в первую очередь отметить мощное развитие большого вертела и ягодичной шероховатости, что соответствует увеличенному размеру и особой нагрузке на все ягодичные мышцы. Таким образом, для данного человека в ходе физических нагрузок были важны и сгибание, и разгибание тазобедренного сустава. Хорошее развитие надмыщелков заставляет предположить повышенную роль сгибания коленного сустава (или, по-другому, голени), а, возможно, и стопы, поскольку, надмыщелки бедра - это место прикрепления трехглавой мышцы голени - главного сгибателя голени и стопы.

Можно также отметить, что на фалангах пальцев кисти усилен рельеф прикрепления мышц сгибателей пальцев.

На первом грудном позвонке вокруг верхних реберных ямок имеются вмятинки-желобки. Вероятно, это генетическая особенность индивида. Не думаем, что эта особенность возникла из-за какой-то особенной нагрузки на первые позвоночно-реберные суставы.

\section{Патологии и травмы}

На правой малоберцовой кости на теле сзади, примерно на границе верхней трети имеются следы небольшого ушиба кости. Имеется небольшая костная опухоль и имеется усиленная васкуляризация в соответствующей области кости. Можно также отметить сильную стертость клыков и резцов, а также несильный зубной камень сзади на нижних молярах. Не исключено, что данный мужчина мог заниматься выделыванием кожи, использую зубы, как инструменты-зажимы. Интересно отметить наличие очень острого сосцевидного гребня на височных костях. Скорее всего, это генетическая особенность.

Скелет из погребения № 8 имел сравнительно хорошую сохранность. На основе измерительных данных были рассчитаны индексы пропорций конечностей и прижизненная длина тела, представленные в таблице 4. Некоторые индексы удалось определить для правой и левой сторон. Для сравнения были использованы данные о размахе вариаций признака у человека современного типа, взятые из работ Я.Я.Ро- 
гинского и М.Г.Левина (Рогинский, Левин 1978), Е.Н.Хрисанфовой (Хрисанфова 1978) и наших собственных работ.

Таблица 4

\section{Индексы пропорций конечностей, показателей таза, прижизненная длина тела индивида из погребения № 8}

\begin{tabular}{|c|c|c|}
\hline Индекс & Правая & Левая \\
\hline Интермембральный индекс (\%) & - & 68,87 \\
\hline Плече-бедренный индекс (\%) & 74,28 & 71,4 \\
\hline Луче-плечевой индекс (\%) & 74,05 & 75,91 \\
\hline Берцово-бедренный индекс (\%) & - & 82,22 \\
\hline Луче-берцовый индекс (\%) & - & 65,92 \\
\hline Ширина таза (см) & \multicolumn{2}{|c|}{$34,4 \mathrm{~cm} *$} \\
\hline Тазо-ростовой индекс (\%) & \multicolumn{2}{|c|}{20,15} \\
\hline Прижизненная длина тела (см) & \multicolumn{2}{|c|}{$170,7 \mathrm{~cm}$} \\
\hline
\end{tabular}

Интермембральный индекс имеет величину ниже среднего, что соответствует несколько укороченным верхним конечностям (точно, левой).

Плече-бедренный индекс, рассчитанный для правой стороны, оказался ультра высоким, и это говорит о сильно удлиненном плече. Левый индекс также имеет довольно высокое значение - выше среднего.

Луче-берцовый индекс имеет значение среднее, относительно размаха вариаций этого индекса для человека современного типа.

Луче-плечевой индекс оказался немного ниже среднего. Это соответствует несколько укороченному предплечью.

Берцово-бедренный индекс, рассчитанный только для левой ноги, имеет среднее значение.

Таким образом, соотношение длин проксимального и медиального отделов верхних и нижних конечностей такое, какое характерно людям континентального адаптивного типа.

Ширина таза была измерена приблизительно. Она составила примерно 34,4 см, что является очень небольшой величиной. Вероятно, действительно, данный индивид характеризовался очень узким тазом, и в абсолютном плане, и относительно длины тела.

Прижизненная длина тела рассчитывалась с учетом длин левых бедренной и большеберцовой костей при помощи формул Пирсона и Ли, Бунака, Дюпертюи и Хеддена. В среднем длина тела составила примерно 170,7 см. То есть, индивид характеризовался большой длиной тела, согласно рубрикации Мартина (цит. по Рогинскому и др., 1978).

В таблице 5 приведены результаты определения показателей массивности (прочности) длинных костей и степени их уплощенности в разных ярусах. Размах вари- 
аций индексов и расшифровка результатов проводилась с использованием данных Я.Я.Рогинского и М.Г.Левина (Рогинский, Левин 1978), Е.Н.Хрисанфовой (Хрисанфова 1978), В.П.Алексеева (Алексеев 1966).

Таблица 5

\section{Индексы массивности (прочности) и укрепленности костей конечностей индивида из погребения № 8}

\begin{tabular}{|c|c|c|}
\hline Индекс & Правая & Левая \\
\hline Индекс прочности плечевой кости (7/1) & 18,66 & 18,18 \\
\hline Индекс массивности лучевой кости (3/1) & 16,54 & 16,37 \\
\hline Индекс сечения лучевой кости (5/4) & 60,53 & 61,11 \\
\hline Индекс массивности локтевой кости (3/2) & 15,57 & 14,64 \\
\hline $\begin{array}{l}\text { Индекс сечения верхней части диафиза локтевой кости } \\
\text { (платолении) (13/14) }\end{array}$ & 81,48 & 80,0 \\
\hline Индекс массивности бедренной кости (8/2) & 18,41 & 18,82 \\
\hline Индекс пилястрии бедра (6/7) & 98,15 & 91,38 \\
\hline Индекс прочности бедра (6+7/2) & 11,59 & 12,01 \\
\hline Индекс платимерии бедра (10/9) & 72,73 & - \\
\hline Индекс массивности большеберцовой кости (10/1) & - & 20,53 \\
\hline Индекс массивности большеберцовой кости (10в/1) & - & 18,42 \\
\hline Индекс расширенности середины диафиза (9/8) & - & 66,13 \\
\hline Индекс платикнемии большеберцовой кости (9a/8a) & - & 73,57 \\
\hline
\end{tabular}

Плечевые кости у данного индивида оказались довольно грацильными и сильно уплощенными в середине диафиза.

Лучевые кости - средне массивны. Кроме того, они очень сильно уплощены в средней части диафиза, у них же очень сильно выступает межкостный край.

Локтевые кости грацильны, также достаточно уплощены в средней области диафиза. В верхней части тела кости средне уплощены, гребень супинатора средне выражен, такие кости называются эуроленичными.

Массивность бедренных костей довольно низкая. Индекс пилястрии ниже 100, что говорит о небольшой сагиттальной уплощенности середины тела костей и слабом развитии шероховатой линии бедра. В верхнем ярусе диафиза кости довольно сильно уплощены в сагиттальном направлении. Индекс платимерии удалось рассчитать только для правой кости. По этому показателю кость гиперплатимерична.

Индексы массивности и уплощенности были рассчитаны только для левой большеберцовой кости. Большеберцовая кость оказалась грацильной. При этом она в средней части тела довольно сильно сплющена в поперечном направлении. А повыше, в районе нахождения питательного отверстия, кость, наоборот, сильно расширена, или эурикнемична. 


\section{Остеоскопия}

В таблице 6 приведены результаты остеоскопии, то есть описания степени развития костного рельефа для прикрепления некоторых наиболее важных мышц, кроме того, здесь приведены результаты описания особенностей костей. Была использована схема описания степени развития мышечного рельефа В.Н. Федосовой (Федосова 1986), в которую нами были добавлены некоторые признаки, также интересные и информативные. Фенетическое описание базировалось на схемах, предложенных в работе В.П. Алексеева «Остеометрия» (Алексеев 1966).

Таблица 6

Оценка степени развития мышечного рельефа и форма некоторых структур костей посткраниального скелета

\begin{tabular}{|c|c|c|}
\hline Кости и структуры & Правая & Левая \\
\hline \multicolumn{3}{|l|}{ Лопатка } \\
\hline Лопаточная вырезка & & 2 \\
\hline Верхний край & & - \\
\hline Латеральный край & & дорзо-маргинальный \\
\hline Подсуставная область & & бугорок \\
\hline Сочленовная впадина & & 2 \\
\hline Лопаточная ость & & - \\
\hline \multicolumn{3}{|l|}{ Плечевая кость } \\
\hline Малый бугорок & 3 & 3 \\
\hline Межбугорковая борозда & 3 & 3 \\
\hline Дельтовидная шероховатость & $1+$ & $1+$ \\
\hline Гребень большого бугорка & $3+$ & $2+$ \\
\hline Гребень малого бугорка & 2 & 2 \\
\hline Гребень супинатора & 2 & $2-$ \\
\hline \multicolumn{3}{|l|}{ Лучевая кость } \\
\hline Лучевая шероховатость & 3 & 3 \\
\hline $\begin{array}{l}\text { Межкостный край } \\
\text { Форма межкостного края }\end{array}$ & $\begin{array}{c}3 \\
\text { прямой }\end{array}$ & $\begin{array}{c}3 \\
\text { вогнутый }\end{array}$ \\
\hline Бугорки и бороздки сзади на нижнем конце & 3 & 3 \\
\hline \multicolumn{3}{|l|}{ Локтевая кость } \\
\hline Локтевая бугристость & 3 & 3 \\
\hline Гребень супинатора & 2 & 2 \\
\hline
\end{tabular}


Таблица 6 (продолжение)

\begin{tabular}{|c|c|c|}
\hline Кости и структуры & Правая & Левая \\
\hline Гребень пронатора & 2 & 1 \\
\hline Задний край & 2 & 2 \\
\hline Межкостный край & 3 & 3 \\
\hline \multicolumn{3}{|l|}{ Бедренная кость } \\
\hline Большой вертел & 3 & - \\
\hline Малый вертел & - & 3 \\
\hline Межвертельный гребень & - & 2 \\
\hline Межвертельная линия & 1 & 2 \\
\hline Шероховатая линия (Linea aspera) & 2 & 1 \\
\hline Ягодичная шероховатость & 2 & - \\
\hline \multicolumn{3}{|c|}{ Развитие надмыщелков (медиальный/латеральный) } \\
\hline \multicolumn{3}{|l|}{ Большеберцовая кость } \\
\hline Большеберцовая бугристость & - & 2 \\
\hline Передний край & - & 2 \\
\hline Межкостный край & - & 2 \\
\hline Линия камбаловидной мышцы & - & 1 \\
\hline Бугорки и бороздки на нижнем конце сзади & - & 1 \\
\hline
\end{tabular}

На плечевой кости можно отметить хорошее развитие рельефа мышц, вращающих плечо внутрь, хорошо выражен рельеф прикрепления большой грудной мышцы, особенно правой. При этом рельеф дельтовидной мышцы, основная функция которой - отведение плеча, развит слабо. Остальной рельеф на костях плеча и предплечья развит достаточно хорошо, за исключением рельефа квадратного пронатора.

На бедренных костях хорошо развиты вертелы. Остальной рельеф, в том числе и ягодичная бугристость, развит умеренно или даже слабо.

\section{Патологии}

Патологии выявлены на поясничных позвонках. У пятого поясничного позвонка наблюдается деформация тела по типу рыбьего позвонка, у остальных позвонков поясничного отдела наблюдается слабая деформация тела, несильный краевой порозистый гиперостоз, в ряде случаев видны признаки остеохондроза. Патологические изменения на позвонках могли возникнуть из-за особых весовых нагрузок на позвоночник, имевших место в ходе жизни. Плечевые кости имеют надмыщелковое отверстие. Крупнее оно слева. 
Также мы заметили несильный, острый краевой гиперостоз на запястной суставной поверхности лучевых костей и головке бедренных костей, а также гиперостоз по краю сочленовной впадины лопаток. Имеются возрастные изменения на фалангах пальцев кисти.

Отмечается также интересная патология: наличие линий Гарриса на большеберцовых костях, говорящие о неравномерном развитии кости с ощутимыми этапами задержки в росте, вызванные, скорее всего, болезнями в детстве. Линии крупные, хорошо заметные, обнаружены на сломе большеберцовых костей.

\section{Изотопный анализ на определение палеодиеты}

Анализ соотношения стабильных изотопов некоторых химических элементов (C, $\mathrm{N})$ в качестве независимого исторического источника прочно вошел в археолого-антропологический исследовательский инструментарий.

Базовые палеодиетологические реконструкции, т.е. определение основных источников питания, входящих в обыденный рацион человека, основаны на экологических закономерностях фракционирования изотопного состава тканей растений и животных при смене трофического уровня. В качестве основного показателя используется $\delta 13 \mathrm{C}$ и $\delta 15 \mathrm{~N}$.

Таблица 7

\section{Изотопный состав углерода и азота в коллагене из образцов «Богомольные пески»}

\begin{tabular}{l|c|c|c}
\hline № анализа & Образец & $\boldsymbol{\delta 1 3 ~ C , ~} \%$ & $\boldsymbol{\delta 1 5 N , ~ \% o ~}$ \\
\hline 3860,3889 & 2. - погр.11. ІІІ тыс. до н.э. & $-19,0$ & 15,5 \\
\hdashline 3864,3893 & 6. --- погр. 9. ІІ тыс. до н.э. & $-17,2$ & 19,0 \\
\hdashline 3865,3894 & 7. --- погр. 7. ІІ тыс. до н.э. & $-17,2$ & 17,5 \\
3867,3896 & 9. -- погр.8. ІІ тыс. до н.э. & $-16,9$ & 18,3 \\
\hdashline 3868,3897 & 10. -- погр.6. ІІ тыс. до н.э. & $-15,1$ & 19,2 \\
\hline 3871,3900 & 13. --- погр. 10. ІІ тыс. до н.э. & $-18,2$ & 17,1 \\
\hline
\end{tabular}

Так в образце из погребения 11 выявлен легкий углерод и умеренно изотопно тяжелый азот, что указывает на то, что в рационе этого человека преобладала мясная пища, возможно мясо птиц. Доля растительной пищи минимальна. У индивидов, относящихся к эпохе бронзы, из погребений $6,7,8,9,10$, определен изотопно легкий углерод и экстремально изотопно тяжелый азот. Это указывает на то, что в рационе этих людей преобладала крупная хищная рыба и мясо водоплавающей птицы. Доля растительной пищи минимальна. Причем максимально тяжелый азот отмечается у детей из погребений 6 и 9.

\section{Заключение}

Таким образом, в курганном могильнике «Богомольные пески» было обнаружено шесть погребений, имеющих датировку II-III тыс. лет до н.э. и относящихся к эпохе 
бронзы. Четыре погребения принадлежали мужчинам в возрасте примерно от 20 до 40 лет, одно - ребенку 5-6 лет и одно ребенку 11-12 лет.

В целом скелеты имели очень плохую сохранность. Отдельные кости двух скелетов, в том числе и немного поврежденные, удалось измерить и провести остеометрический анализ. Расчет индексов пропорций конечностей в целом выявил тенденцию среднего соотношения размеров проксимального и медиального сегментов рук и ног, что характерно для людей континентального адаптивного типа. Интересно, что у обоих индивидов оказалось удлиненным плечо, согласно величине плече-бедренного индекса. Длина тела при жизни, определенная по специальным формулам, оказалась равной 169,0 см и 170,9 см. Это длина тела выше среднего и даже высокая.

Массивность, или прочность, скелетов конечностей у этих мужских индивидов оказалась разной. У индивида из погребения № 7 массивность в целом средняя или выше среднего. В то же время массивность костей рук и ног индивида из погребения № 8 оказалась средней или даже низкой. То есть, скелет этого индивида был более грацильным.

Обнаружены следующие патологии и патологичные изменения на костях. На зубах взрослых индивидов из погребений № 7 и № 11 имеются признаки, предположительно, использования их, как инструментов-зажимов при скорняжных работах.

На зубах ребенка из погребения № 6 имеется эмалевая гипоплазия, возникшая из-за нехватки пищи, недостатка витаминов и, возможно, болезнях в более раннем возрасте.

У индивида из погребения № 7 имеются признаки ушиба задней поверхности тела правой малоберцовой кости.

У мужчины из погребения № 8 обнаружены патологические изменения на позвонках поясничного отдела, вызванные, скорее всего, большими физическими нагрузками в ходе трудовой деятельности.

У двух индивидов (погребение № 8 и погребение № 9, взрослого и ребенка) на сломанных большеберцовых костях были обнаружены так называемые линии Гарриса, - маркеры физиологического стресса, возникающего при нарушении процесса постепенного роста костей. Могло быть вызвано разными причинами, например, болезнями, пищевой и витаминной недостаточностью и другими.

В рационе питания данного населения, согласно данным изотопного анализа, преобладала мясная пища (мясо водоплавающей птицы и хищных рыб) и практически отсутствовала растительная пища. Причем, у детей мясная пища более преобладала в рационе, чем у взрослых мужчин.

\section{Научная литература}

Алексеев В.П. Остеометрия. Методика антропологических исследований. М., 1966.

Мамонова Н.Н. Определение длины костей по их фрагментам // Вопросы антропологии, 1968. № 29. С. 171-177.

Рогинский Я.Я., Левин М.Г. Антропология. М.: МГУ, 1978.

Федосова В.Н. Общая оценка развития компонента мезоморфии по остеологическим данным (остеологическая методика) // Вопросы антропологии. 1986. № 76. С. 104-116. Хрисанфова Е.Н. Эволюционная морфология скелета человека. М.: МГУ, 1978. 


\section{References}

Alekseev, V.P. 1966. Osteometriya. Metodika antropologicheskih issledovanij. [Osteometry. Methodology of anthropological research]. Moscow.

Mamonova, N.N. 1968. Opredelenie dliny kostej po ih fragmentam. [Determination of the length of bones by their fragments]. Voprosy antropologii 29: 171-177.

Roginskij, Ya.Ya., M.G. Levin. 1978. Antropologiya. [Anthropology]. Moscow: Moscow State University.

Fedosova, V.N. 1986. Obshchaya ocenka razvitiya komponenta mezomorfii po osteologicheskim dannym (osteologicheskaya metodika). [General assessment of the development of the component of mesomorphy according to osteological data (osteological technique)]. Voprosy antropologii 76: 104-116.

Hrisanfova, E.N. 1978. Evolyucionnaya morfologiya skeleta cheloveka. [Evolutionary morphology of the human skeleton]. Moscow: Moscow State University.

Vasilyev, Sergei V., Borutskaya, Svetlana B., Vasilyev, Dmitriy V.

\section{Anthropological Analysis of the Bronze Age Burials from Kurgan 1 of the Bogomolniye Peski Burial Ground}

The article focuses on the study of paleoanthropological material from the Lower Volga region, dating back to the Bronze Age. The article provides detailed results of the study of the postcranial skeleton as well as results of the isotope analysis. The study revealed that the Bronze Age diet on this territory was mainly based on poultry and predatory fish. In addition, the isotopic analysis showed that meat played a more important role for children's diet than for adult's one. The morphological analysis of the postcranial skeleton revealed that the humerus was relatively long in this population. The reconstructed length of living men's body resulted above-average.

Key words: Lower Volga, Bronze Age, osteology, osteoscopy, proportions and massiveness of the bones, paleodiet 